\title{
PRODUKSI BIOMASSA DAN KANDUNGAN UNSUR HARA PUPUK HIJAU TURI MINI (Sesbania rostrata) PADA JARAK TANAMAN DAN UMUR PANEN YANG BERBEDA
}

\author{
Basri Baba $^{1)}$, Abbas Karre ${ }^{1)}$, Muhammad Aldi'), Andi Uhti Istiqamah ${ }^{1)}$, Elkawakib \\ Syam'un', Muhammad Riadi ${ }^{2)}$, Muhammad Jayadi' ${ }^{2)}$
}

1) Jurusan Budidaya Tanaman Perkebunan Politeknik Pertanian Negeri Pangkep, Sulawesi Selatan.

2) Fakultas Pertanian Universitas Hasanuddin Makassar, Sulawesi Selatan.

*Email : basribaba67@gmail.com

\begin{abstract}
ABSTRAK
Penelitian ini dilakukan di lapangan untuk mengetahui produksi biomassa dan kandungan unsur hara dari tanaman turi mini (Sesbania rostrata) sebagai pupuk hijau menggunakan jarak tanam dan umur panen yang berbeda. Penelitian dilaksanakan di Dusun Bontouse, Kelurahan Pincengpute, Kecamatan Tanasitolo, Kabupaten Wajo, Provinsi Sulawesi Selatan, Indonesia dari Desember 2018 hingga Juli 2019. Penelitian ini dirancang dengan menggunakan rancangan acak kelompok (RAK) pola faktorial dua faktor. Faktor pertama jarak tanam (j) 3 taraf : $5 \mathrm{~cm}$ x $20 \mathrm{~cm}\left(\mathrm{j}_{1}\right), 10 \mathrm{~cm}$ x $20 \mathrm{~cm}\left(\mathrm{j}_{2}\right), 15 \mathrm{~cm}$ x $20 \mathrm{~cm}\left(\mathrm{j}_{3}\right)$ dan faktor kedua umur panen pupuk hijau $(\mathrm{u})$ dengan 4 taraf : 15 hari $\left(\mathrm{u}_{1}\right), 30$ hari $\left(\mathrm{u}_{2}\right), 45$ hari $\left(\mathrm{u}_{3}\right), 60$ hari $\left(\mathrm{u}_{4}\right)$. Setiap unit perlakuan dibuat bedengan $3 \mathrm{~m}$ x $2 \mathrm{~m}$ dan masing-masing unit perlakuan diulang 3 kali.

Hasil penelitian menunjukkan bahwa rata-rata produksi biomassa kering tanaman turi mini terberat $569 \mathrm{~g} \mathrm{~m}^{-2}$ atau 5,69 ton $\mathrm{ha}^{-1}$ pada jarak tanam $5 \mathrm{~cm} \times 20 \mathrm{~cm}\left(\mathrm{j}_{1}\right)$ dan berbeda nyata dengan jarak tanam $10 \mathrm{~cm} \times 20 \mathrm{~cm}\left(\mathrm{j}_{2}\right)$ serta jarak tanam $15 \mathrm{~cm} \times 20 \mathrm{~cm}\left(\mathrm{j}_{3}\right)$. Untuk umur panen tanaman 60 hari $\left(\mathrm{u}_{4}\right)$ diperoleh rata-rata biomassa kering terberat $1.133 \mathrm{~g} \mathrm{~m}^{-2}$ atau 11,33 ton $\mathrm{ha}^{-}$ ${ }^{1}$ dan berbeda nyata dengan umur panen tanaman 15 hari $\left(\mathrm{u}_{1}\right), 30$ hari $\left(\mathrm{u}_{2}\right)$ dan 45 hari $\left(\mathrm{u}_{3}\right)$. Sedang kandungan unsur hara Sesbania rostrata dengan penggunaan berbagai jarak tanam tidak berbeda nyata; jarak $10 \mathrm{~cm} \times 20 \mathrm{~cm}\left(\mathrm{j}_{1}\right)$ kandungan nitrogen $(\mathrm{N})(4,56 \%)$, produksi posfor $(\mathrm{P})$ tertinggi $(0,24 \%)$. Untuk umur panen 45 hari $\left(\mathrm{u}_{3}\right)$ menghasilkan rata-rata kandungan nitrogen tertinggi $(5,1 \%)$, rata-rata kandungan posfor tertinggi $(0,26 \%)$, dan umur panen 15 hari $\left(\mathrm{u}_{1}\right)$ rata-rata kandungan kalium tertinggi $(6,54 \%)$.
\end{abstract}

Kata kunci: Biomassa, pupuk hijau, unsur hara.

\section{ABSTRACT}

This research was conducted in the field to determine the biomass production and nutrient content of mini turi (Sesbania rostrata) as green manure using different spacing and harvesting ages. The research was conducted in Bontouse Hamlet, Pincengpute Village, Tanasitolo District, Wajo Regency, South Sulawesi Province, Indonesia from December 2018 to July 2019. This study was designed using a two-factor factorial randomized block design (RBD). The first factor is spacing (j) 3 levels: $5 \mathrm{~cm} \mathrm{x} 20 \mathrm{~cm}\left(\mathrm{j}_{1}\right), 10 \mathrm{~cm} \times 20 \mathrm{~cm}\left(\mathrm{j}_{2}\right), 15 \mathrm{~cm} \mathrm{x}$ $20 \mathrm{~cm}\left(\mathrm{j}_{3}\right)$ and the second factor is the age of green manure harvest (u) with 4 levels: 15 days $\left(\mathrm{u}_{1}\right), 30$ days $\left(\mathrm{u}_{2}\right), 45$ days $\left(\mathrm{u}_{3}\right), 60$ days $\left(\mathrm{u}_{4}\right)$. Each treatment unit was made $3 \times 2 \mathrm{~m}$ beds and each treatment unit was repeated 3 times.

The results showed that the average dry biomass production of turi mini plants was 569 $\mathrm{g} \mathrm{m}^{-2}$ or 5.69 tonnes $\mathrm{ha}^{-1}$ at a spacing of $5 \mathrm{~cm} \times 20 \mathrm{~cm}\left(\mathrm{j}_{1}\right)$ and was significantly different from the spacing of $10 \mathrm{~cm} \times 20 \mathrm{~cm}\left(\mathrm{j}_{2}\right)$ and the spacing of $15 \mathrm{~cm} \times 20 \mathrm{~cm}\left(\mathrm{j}_{3}\right)$. For the plant harvesting 
age of 60 days $\left(\mathrm{u}_{4}\right)$, the heaviest average dry biomass was $1,133 \mathrm{~g} \mathrm{~m}^{-2}$ or 11.33 tonnes ha- ${ }^{-1}$ and was significantly different from the plant harvest age of 15 days $\left(\mathrm{u}_{1}\right), 30$ days $\left(\mathrm{u}_{2}\right)$ and 45 days $\left(u_{3}\right)$. While the nutrient content of Sesbania rostrata with the use of various spacing was not significantly different; distance of $10 \mathrm{~cm} \times 20 \mathrm{~cm}\left(\mathrm{j}_{1}\right)$ nitrogen $(\mathrm{N})$ content $(4.56 \%)$, the highest phosphorus $(\mathrm{P})$ production $(0.24 \%)$. The harvest age of 45 days $\left(\mathrm{u}_{3}\right)$ produced the highest average nitrogen content $(5.1 \%)$, the highest average phosphorus content $(0.26 \%)$, and the harvest age of 15 days $\left(\mathrm{u}_{1}\right)$ the highest average potassium content $(6.54 \%)$.

Keywords: Biomass, green manure, nutrients.

\section{PENDAHULUAN}

Pupuk hijau merupakan salah satu pupuk organik yang berasal dari tanaman atau sisa tanaman yang dimanfaatkan untuk meningkatkan kandungan bahan organik dan unsur hara tanah sehingga sifat fisika, kimia dan biologi tanah menjadi baik. Bahan tanaman sebagai bahan pupuk hijau dibenam dalam bentuk masih hijau atau setelah dikomposkan.

Turi mini (Sesbania rostrata) merupakan tanaman yang berpotensi sebagai pupuk hijau, karena tanaman turi mini dapat dimanfaatkan sebagai sumber bahan organik untuk memperbaiki kesuburan tanah, meningkatan kapasitas tanah dalam menyerap unsur hara, memperbaiki struktur tanah, dan meningkatkan aktivitas mikroba tanah. S. rostrata adalah sejenis tanaman kacang-kacangan (Leguminosa) yang dapat menambat nitrogen dari udara melalui akar dan batang, dapat tumbuh dalam kondisi kering atau tergenang. Potensi S. rostrata sebagai penyubur tanah ditunjang oleh sifat perakarannya yang cukup dalam dan banyak mengandung bintil-bintil akar (Arunin et al., 1988). Tanaman S. rostrata yang ditanaman dengan menggunakan biji sekitar $2 \mathrm{~kg} \mathrm{ha}^{-1}$ dapat menghasilkan biomassa sebesar 12,5 ton ha 1. Tanaman ini sangat potensial dijadikan pupuk hijau karena mampu hidup di lahan kering maupun lahan tergenang. Pada akar dan batangnya terdapat banyak bintil-bintil yang merupakan simbiosis dengan Rhizobium sehingga dapat memfiksasi nitrogen dari udara. Tanaman ini mampu memfiksasi nitrogen 10 kali lebih besar dari tanaman legume lainnya. $S$. rostrata yang dibenamkan pada umur 45 hari dapat menyumbang $75 \mathrm{~kg} \mathrm{ha}^{-1}$ nitrogen, $5 \mathrm{~kg} \mathrm{ha}^{-}$

1 fosfat, dan $18 \mathrm{~kg} \mathrm{ha}^{-1}$ kalium. S. rostrata mempunyai kemampuan yang tinggi dalam menambat $\mathrm{N}$ dari udara sebanyak $200 \mathrm{~kg} \mathrm{~N}_{2}$ ha $^{-1}$ dalam waktu 50 hari (Arunin et al., (1988).

Hasil penelitian di IRRI (1990) menunjukkan bahwa S. rostrata yang ditanam pada musim kemarau dengan populasi 500.000 tanaman $\mathrm{ha}^{-1}$ dapat mengikat $\mathrm{N}$ sebanyak $240,3 \mathrm{~kg}$ $\mathrm{ha}^{-1}$ dan yang ditanam pada musim hujan dengan populasi yang sama pada saat umur 55 hari dapat mengikat $\mathrm{N}$ sebanyak $285,7 \mathrm{~kg} \mathrm{ha}^{-1}$. S. rostrata dengan umur 13 minggu menghasilkan biomassa kering 16,8 ton $\mathrm{ha}^{-1}$ dan mengandung $426 \mathrm{~kg} \mathrm{~N}$ ha $^{-1}$, sekitar $75 \% \mathrm{~N}$ dan lebih dari 
60\% P yang diakumulasikan di daun (Saraswati dan Matoh, 1993). Penanaman S. rostrata pada luas lahan 1 ha menggunakan $2 \mathrm{~kg}$ biji, dapat menghasilkan biomassa 12,5 ton, nitrogen $75 \mathrm{~kg}$, fosfat $5 \mathrm{~kg}$, dan kalium $18 \mathrm{~kg}$ (Adiningsih dan Rochayati 1988).

Pemanfaatan turi mini selama ini, baik dalam bentuk segar maupun hasil olahan belum dapat diketahui secara tepat hasil biomassa dengan kandungan unsur haranya. Sehingga penanaman turi mini dalam setiap satuan luasnya, belum dapat diperkirakan jumlah biomassa yang dihasilkan dengan kandungan unsur haranya berdasarkan jarak tanam dan umur panen yang berbeda.

Berdasarkan hal tersebut di atas maka penelitian ini dilakukan untuk mengetahui produksi biomassa dan kandungan unsur hara pupuk hijau Sesbania rostrata pada jarak tanam dan umur panen yang berbeda.

\section{BAHAN DAN METODE}

Penilitian dilaksanakan di Dusun Bontouse, Kelurahan Pincengpute, Kecamatan Tanasitolo, Kabupaten Wajo, Provinsi Sulawesi Selatan, Indonesia dari Desember 2018 hingga Juli 2019. Bahan dan alat yang digunakan terdiri dari benih Sesbania rostrata, label, tali rapiah, tali nilon, kultivator, timbangan, parang, alat tulis menulis. Penelitian ini menggunakan rancangan acak kelompok (RAK) pola faktorial dua faktor. Faktor pertama jarak tanam (j) 3 taraf : $5 \mathrm{~cm}$ x 20 $\mathrm{cm}\left(\mathrm{j}_{1}\right), 10 \mathrm{~cm} \times 20 \mathrm{~cm}\left(\mathrm{j}_{2}\right), 15 \mathrm{~cm}$ x $20 \mathrm{~cm}\left(\mathrm{j}_{3}\right)$ dan faktor kedua umur panen pupuk hijau (u) dengan 4 taraf : 15 hari $\left(\mathrm{u}_{1}\right), 30$ hari $\left(\mathrm{u}_{2}\right), 45$ hari $\left(\mathrm{u}_{3}\right), 60$ hari $\left(\mathrm{u}_{4}\right)$. Adapun kombinasi perlakuan yang diberikan adalah : $5 \mathrm{~cm}$ x $20 \mathrm{~cm}+$ umur panen $15 \mathrm{HST}\left(\mathrm{j}_{1} \mathrm{u}_{1}\right), 5 \mathrm{~cm}$ x $20 \mathrm{~cm}+$ umur panen $30 \operatorname{HST}\left(\mathrm{j}_{1} \mathrm{u}_{2}\right), 5 \mathrm{~cm} \times 20 \mathrm{~cm}+$ umur panen $45 \mathrm{HST}\left(\mathrm{j}_{1} \mathrm{u}_{3}\right), 5 \mathrm{~cm} \times 20 \mathrm{~cm}+$ umur panen $60 \mathrm{HST}$ $\left(\mathrm{j}_{1} \mathrm{u}_{4}\right), 10 \mathrm{~cm} \times 20 \mathrm{~cm}+$ umur panen $15 \operatorname{HST}\left(\mathrm{j}_{2} \mathrm{u}_{1}\right), 10 \mathrm{~cm} \times 20 \mathrm{~cm}+$ umur panen $30 \mathrm{HST}\left(\mathrm{j}_{2} \mathrm{u}_{2}\right)$, $10 \mathrm{~cm} \times 20 \mathrm{~cm}+$ umur panen $45 \mathrm{HST}\left(\mathrm{j}_{2} \mathrm{u}_{3}\right), 10 \mathrm{~cm} \times 20 \mathrm{~cm}+$ umur panen $60 \mathrm{HST}\left(\mathrm{j}_{2} \mathrm{u}_{4}\right), 15$ $\mathrm{cm} \times 20 \mathrm{~cm}+$ umur panen $15 \mathrm{HST}\left(\mathrm{j}_{3} \mathrm{u}_{1}\right), 15 \mathrm{~cm}$ x $20 \mathrm{~cm}+$ umur panen $30 \mathrm{HST}\left(\mathrm{j}_{3} \mathrm{u}_{2}\right), 15 \mathrm{~cm}$ x $20 \mathrm{~cm}$ + umur panen $45 \mathrm{HST}\left(\mathrm{j}_{3} \mathrm{u}_{3}\right), 15 \mathrm{~cm}$ x $20 \mathrm{~cm}+$ umur panen $60 \mathrm{HST}\left(\mathrm{j}_{3} \mathrm{u}_{4}\right)$.

Penelitian dilakukan dengan tahapan sebagai berikut: lahan diolah dan dibagi menjadi 3 ulangan, kemudian dibuat bedengan dengan ukuran $3 \mathrm{~m}$ x $2 \mathrm{~m}$ untuk setiap unit perlakuan, setiap ulangan terdiri 12 bedengan sehingga dibutukan 36 bedengan. Penanaman turi mini dilakukan dengan jarak tanam sesuai perlakuan. Pemeliharaan tanaman turi mini dilakukan sampai panen dengan penyulaman, penyiangan dan pengairan. Panen turi mini dilakukan sesuai perlakuan dengan mencabut tanaman sehingga semua bagian tanaman (akar, batang, dan daun) diperoleh. 
Parameter yang diamati di penelitian ini diantaranya: berat biomassa tanaman, kandungan unsur hara. Berat biomassa diperoleh berdasarkan waktu panen sesuai perlakuan. Tanaman turi mini hasil panen dicacah, kemudian ditimbang untuk diperoleh berat biomassa turi mini. Untuk mengetahui kandungan unsur hara tanaman turi mini maka cacahan mulai dari akar, batang, bagian ujung, dan daun diambil sebanyak $250 \mathrm{~g}$ kemudian dibawa ke labaratorium Tanah, Tanaman, Pupuk, Air Badan Penelitian dan Pengembangan Pertanian Balai Pengkajian Teknologi Pertanian Sulawesi Selatan, untuk dianalisa unsur haranya, yaitu N, P, dan K.

\section{HASIL DAN PEMBAHASAN}

\section{Produksi Biomassa}

Hasil analisis biomassa tanaman turi mini pada tabel 1 menunjukkan bahwa jarak tanam $5 \mathrm{~cm} \times 20 \mathrm{~cm}\left(\mathrm{j}_{1}\right)$ menghasilkan rata-rata biomassa kering terberat $\left(569 \mathrm{~g} \mathrm{~m}^{-2}\right.$ atau 5,6 ton ha ${ }^{1}$ ) dan berbeda nyata dengan jarak tanam $10 \mathrm{~cm} \times 20 \mathrm{~cm}\left(\mathrm{j}_{2}\right)$ serta jarak tanam $15 \mathrm{~cm} \times 20 \mathrm{~cm}$ (j3).

Sedangkan umur tanaman 60 hari $\left(\mathrm{u}_{4}\right)$ menghasilkan rata-rata biomassa terberat $(1.133 \mathrm{~g}$ $\mathrm{m}^{-2}$ atau atau 11,33 ton $\left.\mathrm{ha}^{-1}\right)$ dan berbeda nyata dengan umur tanaman 15 hari $\left(\mathrm{u}_{1}\right), 30$ hari $\left(\mathrm{u}_{2}\right)$ dan 45 hari $\left(\mathrm{u}_{3}\right)$.

Tabel 1. Rata-rata produksi biomassa kering S. rostrata

\begin{tabular}{ccccccc}
\hline \multirow{2}{*}{$\begin{array}{c}\text { Jarak Tanam } \\
(\mathrm{cm})\end{array}$} & $15\left(\mathrm{u}_{1}\right)$ & $30\left(\mathrm{u}_{2}\right)$ & $45\left(\mathrm{u}_{3}\right)$ & $60\left(\mathrm{u}_{4}\right)$ & $\begin{array}{c}\text { Rata- } \\
\text { rata }\end{array}$ & $\begin{array}{c}\mathrm{NP} \\
\mathrm{BNT}_{0,05}\end{array}$ \\
\hline $5 \times 20\left(\mathrm{j}_{1}\right)$ & 0,48 & 2,66 & 7,34 & 12,27 & $5,69^{\mathrm{a}}$ & 0,5782 \\
$10 \times 20\left(\mathrm{j}_{2}\right)$ & 0,29 & 2,08 & 5,81 & 11,34 & $4,88^{\mathrm{b}}$ & \\
$15 \times 20\left(\mathrm{j}_{3}\right)$ & 0,23 & 1,73 & 4,29 & 10,37 & $4,16^{\mathrm{c}}$ & \\
\hline Rata-rata $^{\mathrm{n}}$ & $0,33^{\mathrm{d}}$ & $2,16^{\mathrm{c}}$ & $5,82^{\mathrm{b}}$ & $11,33^{\mathrm{a}}$ \\
\hline $\mathrm{NP} \mathrm{BNT}_{0,05}$ & 0,6676 & & & \\
\hline Keterangan & Angka-angka yang diikuti oleh huruf yang sama pada baris dan kolom yang sama berarti
\end{tabular}

Hasil analisis uji lanjut menunjukkan bahwa pencapaian biomassa Sesbania rostrata tertinggi diperoleh pada jarak tanam $5 \mathrm{~cm} \times 20 \mathrm{~cm}\left(\mathrm{j}_{1}\right)$. Jarak tanam tersebut merupakan jarak tanam yang paling rapat dari jarak tanam yang dicobakan. Jarak tanam dapat mempengaruhi populasi tanaman, dengan semakin rapatnya jarak tanam berarti akan semakin banyak jumlah populasi tanaman. Menurut Hidayat dan Purboyo (1984), dengan bertambahnya populasi tanaman yang berada dalam keadaan normal, tanpa adanya persaingan antar tanaman, maka 
diharapkan produksi per satuan luas juga akan lebih tinggi. Hal ini juga akan menyebabkan pertambahan biomassa tanaman.

Menurut Michael (1994), biomassa didefinisikan sebagai jumlah total bahan hidup pada suatu waktu tertentu suatu luas tertentu. Ditambahkan Sutjipto (1992) biomassa meliputi seluruh tubuh makhluk yang hidup walaupun bagian tubuh itu seperti cabang atau daun pada pohon asalkan masih melekat pada tumbuhan tersebut. Menurut Sitompul dan Guritno (1995) pengukuran biomassa total tanaman merupakan parameter yang baik yang dapat digunakan sebagai indikator pertumbuhan tanaman. Hal ini didasarkan pada kenyataan bahwa taksiran biomassa tanaman relatif mudah diukur dan merupakan integrasi dari hampir semua peristiwa yang dialami tanaman sebelumnya.

\section{Kandungan Unsur Hara}

\section{- Unsur Nitrogen (N)}

Produksi nitrogen $S$. rostrata pada berbagai jarak tanam berpengaruh tidak nyata, umur panen tanaman sangat berpengaruh nyata, sedangkan interaksi keduanya berpengaruh tidak nyata terhadap kandungan nitrogen $S$. rostrata.

Tabel 2. Rata-rata kandungan nitrogen S. rostrata

\begin{tabular}{cccccc}
\hline \multirow{2}{*}{$\begin{array}{c}\text { Jarak Tanam } \\
(\mathrm{cm})\end{array}$} & $15\left(\mathrm{u}_{1}\right)$ & $30\left(\mathrm{u}_{2}\right)$ & $45\left(\mathrm{u}_{3}\right)$ & $60\left(\mathrm{u}_{4}\right)$ & Rata-rata \\
\cline { 2 - 5 } & 4,44 & 4,27 & 5,09 & 4,10 & 4,48 \\
$10 \times 20\left(\mathrm{j}_{1}\right)$ & 4,42 & 4,55 & 5,02 & 4,23 & 4,56 \\
$15 \times 20\left(\mathrm{j}_{2}\right)$ & 4,36 & 4,28 & 5,24 & 4,29 & 4,54 \\
\hline Rata-rata & $\left.4,41^{\mathrm{b}}\right)$ & $4,37^{\mathrm{b}}$ & $5,11^{\mathrm{a}}$ & $4,21^{\mathrm{c}}$ \\
\hline $\mathrm{NP} \mathrm{BNT}_{0,05}$ & 0,1484 & \multicolumn{5}{c}{} \\
\hline Keterangan & $:$ & Angka-angka yang dikuti oleh huruf yang sama pada baris yang sama berarti berbeda tidak \\
& nyata pada taraf uji BNT $\alpha_{0,05}$
\end{tabular}

Tabel 2 menunjukkan bahwa umur panen 45 hari $\left(\mathrm{u}_{3}\right)$ menghasilkan rata-rata produksi nitrogen tertinggi $(5,11 \%)$ dan berbeda nyata dengan umur panen 15 hari $\left(\mathrm{u}_{1}\right), 30$ hari $\left(\mathrm{u}_{2}\right)$ dan 60 hari $\left(u_{4}\right)$.

\section{- Unsur Posfor}

Produksi posfor S. rostrata pada berbagai jarak tanam berpengaruh tidak nyata, umur tanaman berpengaruh sangat nyata, sedangkan interaksi keduanya berpengaruh tidak nyata terhadap produksi posfor S. rostrata. 
Tabel 3. Rata-rata produksi Posfor Sesbania rostrata

\begin{tabular}{|c|c|c|c|c|c|}
\hline \multirow{2}{*}{$\begin{array}{l}\text { Jarak Tanam } \\
(\mathrm{cm})\end{array}$} & \multicolumn{4}{|c|}{ Umur Panen (hari) } & \multirow{2}{*}{ Rata-rata } \\
\hline & $\mathrm{u}_{1}$ & $\mathrm{u}_{2}$ & $\mathrm{u}_{3}$ & $\mathrm{u}_{4}$ & \\
\hline $5 \times 20\left(\mathrm{j}_{1}\right)$ & 0,22 & 0,26 & 0,25 & 0,23 & 0,24 \\
\hline $10 \times 20\left(\mathrm{j}_{2}\right)$ & 0,21 & 0,25 & 0,28 & 0,22 & 0,24 \\
\hline $15 \times 20\left(\mathrm{j}_{3}\right)$ & 0,19 & 0,24 & 0,24 & 0,22 & 0,22 \\
\hline Rata-rata & $0,21^{\mathrm{c}}$ & $0,25^{\mathrm{ab}}$ & $0,26^{\mathrm{a}}$ & $0,23^{\mathrm{bc}}$ & \\
\hline $\mathrm{NP} \mathrm{BNT}_{0,05}$ & 0,0249 & & & & \\
\hline
\end{tabular}

Tabel 3 menunjukkan bahwa umur panen 45 hari $\left(\mathrm{u}_{3}\right)$ menghasilkan rata-rata produksi posfor tertinggi $(0,26 \%)$ dan berbeda nyata dengan umur panen 15 hari $\left(\mathrm{u}_{1}\right), 30$ hari $\left(\mathrm{u}_{2}\right)$ dan 60 hari $\left(u_{4}\right)$.

\section{- Unsur Kalium}

Produksi kalium S. rostrata pada berbagai jarak tanam berpengaruh tidak nyata, umur panen berpengaruh sangat nyata, sedangkan interaksi keduanya berpengaruh tidak nyata terhadap kandungan kalium Sesbania rostrata.

Tabel 4. Rata-Rata Kandungan Kalium Sesbania rostrata.

\begin{tabular}{cccccc}
\hline \multirow{2}{*}{$\begin{array}{c}\text { Jumlah } \\
\text { penebaran } \\
\left(\mathrm{g} \mathrm{m}^{-2}\right)\end{array}$} & $15\left(\mathrm{u}_{1}\right)$ & $30\left(\mathrm{u}_{2}\right)$ & $45\left(\mathrm{u}_{3}\right)$ & $60\left(\mathrm{u}_{4}\right)$ & Rata-rata \\
\cline { 2 - 5 } & 6,39 & 4,27 & 4,88 & 3,47 & 4,75 \\
$10 \times 20\left(\mathrm{j}_{1}\right)$ & 6,76 & 3,94 & 4,51 & 3,45 & 4,66 \\
$15 \times 20\left(\mathrm{j}_{3}\right)$ & 6,46 & 4,05 & 4,26 & 3,45 & 4,56 \\
\hline Rata-rata & $6,54^{\mathrm{a}}$ & $4,08^{\mathrm{c}}$ & $4,55^{\mathrm{b}}$ & $3,46^{\mathrm{d}}$ & \\
\hline NP BNT $_{0,05}$ & 0,3498 & & & & \\
\hline
\end{tabular}

Keterangan : Angka-angka yang diikuti oleh huruf yang sama pada baris yang sama berarti berbeda tidak nyata pada taraf uji BNT $\alpha_{0,05}$

Tabel 4 menunjukkan bahwa umur panen 15 hari $\left(\mathrm{u}_{1}\right)$ menghasilkan rata-rata kandungan kalium tertinggi $(6,54 \%)$ dan berbeda nyata dengan umur panen 30 hari $\left(\mathrm{u}_{2}\right), 45$ hari $\left(\mathrm{u}_{3}\right)$ dan 60 hari $\left(\mathrm{u}_{4}\right)$.

Hasil analisis menunjukkan bahwa kandungan hara fosfor dan kalium pada turi mini dengan perlakuan jarak tanam $5 \mathrm{~cm} \times 20 \mathrm{~cm}\left(\mathrm{j}_{1}\right)$ diduga berkaitan dengan ruang tanaman yang lebih rapat dibandingkan yang lain sehingga populasi yang dihasilkan juga lebih banyak, dengan semakin tingginya populasi berarti jumlah hara juga semakin tinggi $(\mathrm{N}, \mathrm{P}$, dan $\mathrm{K})$ yang bisa diperoleh per satuan luas. Sesuai pernyataan Harjadi (1996), bahwa pada suatu lahan yang 
mempunyai populasi yang tinggi umumnya dapat meningkatkan jumlah hara tanaman. Selanjutnya Menurut Suprapto (1992), bahwa adanya pengaturan pada jarak tanam berimplikasi terhadap hasil persatuan luas. Umur panen 45 hari $\left(\mathrm{u}_{3}\right)$ dicapai kandungan hara tertinggi yaitu nitrogen $(5,11 \%)$ dan fosfor $(0,26 \%)$. Sedangkan umur panen 15 hari $\left(\mathrm{u}_{1}\right)$ diperoleh kandungan kalium yang tertinggi (6,54\%). Hal ini diduga disebabkan umur 45 hari dan 15 hari merupakan umur yang optimal dalam menghasilkan kandungan unsur hara nitrogen, fosfor, dan kalium.

\section{KESIMPULAN}

1. Rata-rata produksi biomassa turi mini terberat $569 \mathrm{~g} \mathrm{~m}^{-2}$ atau 5,69 ton ha ${ }^{-1}$ pada jarak tanam $5 \mathrm{~cm} \times 20 \mathrm{~cm}\left(\mathrm{j}_{1}\right)$ dan berbeda nyata dengan jarak tanam $10 \mathrm{~cm} \times 20 \mathrm{~cm}\left(\mathrm{j}_{2}\right) \mathrm{serta}$ jarak tanam $15 \mathrm{~cm} \times 20 \mathrm{~cm}\left(\mathrm{j}_{3}\right)$.

2. Untuk umur panen tanaman 60 hari $\left(\mathrm{u}_{4}\right)$ diperoleh rata-rata biomassa terberat $1.133 \mathrm{~g} \mathrm{~m}^{-2}$ atau 11,33 ton $\mathrm{ha}^{-1}$ dan berbeda nyata dengan umur panen tanaman 15 hari $\left(\mathrm{u}_{1}\right), 30$ hari $\left(\mathrm{u}_{2}\right)$ dan 45 hari $\left(\mathrm{u}_{3}\right)$.

3. Kandungan unsur hara Sesbania rostrata pada umur panen 45 hari $\left(\mathrm{u}_{3}\right)$ menghasilkan kandungan nitrogen $(\mathrm{N})$ tertinggi $(5,11 \%)$, kandungan posfor $(\mathrm{P})$ tertinggi $(0,26 \%)$, dan kandungankalium $(\mathrm{K})$ tertinggi $(6,54 \%)$ dicapai pada umur panen 15 hari $\left(\mathrm{u}_{1}\right)$.

\section{UCAPAN TERIMA KASIH}

Disampaikan terima kasih dan penghargaan kepada Direktorat Jenderal Pendidikan Vokasi, Kementerian Pendidikan dan Kebudayaan (Kemendikbud) yang telah mendanai penelitian ini.

\section{DAFTAR PUSTAKA}

Adiningsih, J.S. dan S. Rochayati. 1988. Peranan Bahan Organik dalam Meningkatkan Efisiensi Penggunaan Pupuk dan Produktivitas Lahan. Prosiding disajikan dalam Lokakarya Efisiensi Pupuk. Cipayung, 16-17 November 1987.

Arunin, S., C. Dissataporn, Y. Anuluxtipan, and D. Nana. 1988. Potential of Sesbania as a Green Manure in Saline Rice Soils in Thailand. p.83-95. In: M.LR. Pollard and G. Argosino (eds.) Green Manure in Rice Farming. Internat. Rice Res. Inst., Los Banos, Philippines.

Harjadi, S.S. 1996. Pengantar Agronomi. PT Gramedia Pustaka Utama. Jakarta. 197 hal.

Hidayat, O. O. dan I. Purboyo. 1984. Groundnut Production, Utilization and Further Research Needs In Indonesia. Indonesian Agriculture Research and Development 
Journal 6 (3 and 4). The Ministery of Agriculture Agency For Agriculture Research and Development. Jakarta.

International Rice Research Institute. 1990. Estimating Nitrogen Fixation by Sesbania rostrata and S. cannabina in Lowland Rice Soil by 15N Dilution Method. in: Program Report for 1989. Los Banos, Laguna, Philippines. 76-77.

Michael P. 1994. Metode ekologi untuk penyelidikan lapangan dan laboratorium. UI Press. Jakarta.

Saraswati, R. dan T. Matoh. 1993. Toleransi Terhadap Cekaman Edafik dan Penambatan Nitrogen Genus Sesbania. Penelitian Pertanian. 13 (1): 36-40.

Sitompul, S. M. dan Guritno, B. 1995. Analisis Pertumbuhan Tanaman. UGM Press: Yogjakarta

Suprapto, J. 1992. Teknik Sampling Untuk Survey dan Eksperimen. Rinika Cipta: Jakarta. 